

\section{Understanding colour}

Colour is extremely difficult to explain and understand except through generalised observations of hue such as blue, blueish-grey or brown (Ksiazkiewicz, 2013). The definition of colour remains a subject of debate among colour scientists. Colour can be interpreted as an objective matter when understood as physical phenomenon. But colour can also be interpreted as a subjective matter due to a physical stimulus, which is not considered as a subject of study in this paper, or even like a personal sensation. In general, there are three different interpretations of colour, one from physics, and another from psychophysics and the last one from psychology (Urland, 1999; Byrne and Hilbert, 2003).

In conservation and restoration we understand colour as a result of the intensity of the electromagnetic waves over the objects, but also having in mind the luminance (light sources), the reflectance (objects), the colour sensation and colour vision (highly influenced by eye health, age). As a result, the concepts and terms are easily confused. But even without having in mind the physical considerations, each observer interprets colour based on personal preferences and references. The way to verbally describe and compare a colour with accuracy is using an measurement instrument that explicitly identifies the colour being measured and assigns it a numeric value - the spectrophotometer. (X-Rite, 2015: 23-29).

Because of the practical need to describe colours accurately and to be able to communicate about them, the colour order systems were developed. With these systems it is possible to identify a single colour, to analyse the relationship among colours and to choose and match colours. This systems are not new. Making order in the vast set of colours that humans are able to distinguish has existed since the ancient times. Philosophers, scientists, architects, artists, and writers are some of the people who have proposed some kind of colour order systems, like Aristotle (c.350 BC) or Leonardo da Vinci (1516), Isaac Newton (1704) and Johann W. Goethe (1810). In the twentieth century the most eminent experts were Albert H. Munsell (1905, 1907, and 1915), Wilhelm Ostwald (1916, 1917), Cándido Villalobos and Julio Villalobos-Domínguez (1947), Harald Kuppers (1978) among others. This kind of approach, of creating an organized system to identify colours, has also been pursued by organizations such as the Commission Internationale de l'Eclairage $(1931,1976)$, the Optical Society of America (1947-1977), the Swedish Standards Institution (1979), and others (Nemcsicsa and Caivano, 2015).

But in the particular case of conservation practice, for the retouching process conservators-restorers (C\&R) need to identify the pigments present in the artwork and the binding medium to have enough data to decide which kind of paint would be suitable to perform the retouching. Conservators-restorers make use of pigments and dyes as powder to add to natural or synthetic resins, or ready- made paints, normally from fine arts materials. Afterwards the retouching technique is decided and the C\&R starts to reproduce hues, tints, shades and tones according with the original paint layer. The difficulty of describing this particular stage is indeed very evident. Students and professionals of conservation-restoration field usually write the brand and the name of the paint present in the label, for example "Cadmium Orange Hue" from Winsor \& Newton Watercolours. But is this information sufficient and accurate?

\section{Labeling Color}

The term Hue often found in student grade paints (not in artist or professional grade) is normally used to label all colour-pigment that differ from the pure hue, in other words, the paint tube of Cadmium Orange Hue don't have pure Cadmium Orange. In these cases, the hues are made from alternative pigments, usually less expensive, but with similarities in terms of the qualitative attributes of the colour-pigment (hue, saturation and luminosity)(Pyle and Pearce 2009: 17; Martel 1855: 9; Bailão, 2015: 116). The Hue word can also be used to specify the discontinued, historical colours like Indian Yellow, Vandyke Brown, and Sap Green. The intent is to provide information about paint composition and about unavailable colours. However, the best option is to always use professional grade paints because they are made of the purest and highest-quality pigments, with more quantity of pigments and less additives which will contribute to the permanency of the paint.

One question usually came up when talking about retouching. Which kind of information should the conservator-restorer search for? Information such as toxicity, permanency and pigments context are normally available in the label of the professional pigments/paints or in the website of the manufacture. One of the most important data is the Colour Index Name. The standard method for naming pigments worldwide is through the Colour Index generic name and number, plus the five digit constitution number of each pigment or dye. This system is a result of a joint effort of the Society of Dyers and Colourists of the Great Britain and the American Association of Textile Chemists and Colourists in the United States (Society of Dyers and Colourists, 2019). It provides an internationally recognized, standardized, and dependable way for a conservator-restorer to know precisely which pigments are in a paint. Even if a paint is entitled with a colour name bearing no relationship to the actual ingredients, and therefore not in agreement with ASTM standards, the Colour Index information is the only system to rely on. But the accuracy of the labels remains very much a matter of trust as the ASTM has no enforcement role. One example of this circumstance are the seven new Cadmium-Free watercolours introduced by Winsor \& Newton in 2019. There are no information about the pigments they contain on their paint labels nor on the website of the manufacturer. According to the 
investigation of the blogger Peter Ward, Winsor \& Newton 'cannot give the pigments away for other companies to use." Furthermore he records "we spent years perfecting these colours to mimic as close as possible the original Cads and we are protecting our own interests"[1]. In retouching practice the absence of such data is a problem, because the conservators-restorers don't know what kind of pigments are present in the paints. Also, it is necessary to specify the pigments used in the process due to future alterations of the final colour.

\section{Colour Index Name}

All pigments are in a single generic class, pigments $(P)$, with the exception of some pigments and dyes. The hue description follows the use description. There are nine hue descriptions: red $(R)$, orange $(O)$, yellow $(Y)$, green $(G)$, blue $(B)$, violet $(\mathrm{V})$, brown $(\mathrm{Br})$, black $(\mathrm{Bk})$ and White $(\mathrm{W})$. The generic number following the name refers to the particular type of pigment. Example: the Colour Index generic name and number of natural barites, $\mathrm{BaSO} 4$, is Pigment White 22 (PW 22) or for cadmium zinc sulfoselenide (CdS, CdSe) which is Pigment Red 108 (PR 108).

But after the generic name and number the label could also contain a five-digit constitution number to indicate the chemical constitution of each colorant when it is known. According with Johnston-Feller (2001:296-297), blocks of numbers have been assigned according to general chemical character of the pigment. Thus, all natural pigments are given numbers from 75000 to 75999; inorganic pigments are assigned numbers from 77000 to 77999 and phthalocyanine from 74000 to 74999 (Eastaugh, 2008; Berrie And Lomax, 1997: 10). But, as the example mention above, with the Cadmium-Free watercolours, there are paints that contain pigments that are not registered with the ASTM. The information is kept by the manufacture. This means that the ASTM has not given it a Colour Index number.

But the Colour Index Name have also limitations because the Index does not necessarily express what the real hue of the colour will be. This is due to a wide range of shades in a pigment that can still share the same Color Index Name. Cadmium Red pigment PR 108 can be taken as an example. The PR 108 could indicate a very warm Cadmium Red Light or a much cooler and deeper Cadmium Red Deep. The same Index are used to label two different shades. The synthetic iron oxide, PR 101, belongs both to the dense and opaque Violet Oxide and the very translucent Transparent Red Iron Oxide. The advantage of the Index is clear understanding of the pigment used in the composition of the paint.

\section{The colour mixing descriptions}

Properties such as transparency/opacity - when the paint is simply applied thickly (masstone) or thinly (undertone)
- or if the paint has the ability to change the character of another colour (tinting strength) are simpler to describe. One of the most usual information on chromatic reintegration present in the final report after treatment is about the brands supplied to make the treatment. Some conservators-restorers also specify the exact pigments used writing the generic name while others record the Colour Index name and the number. But one question arises: how to describe and write the colour mixings?

It is possible to specify the pigment used for the mixing, the mixing itself and the quantity of pigment. As mention above, the tendency to use the generic name written by the manufactures in the label of the tube paint is not sufficient for the conservator-restorer since the common name is not always precise, i.e., it doesn't always have a correlation with the paint composition. Also, depending of the brands, a colour can also change. It can be pure, with one pigment, or it could be made with two or more pigments. It is necessary to be more specific.

The kind of information that the conservator-restorer needs to describe can be correlated by analogy with an equation. The colour index name, the adding pigments and the quantity can directly state in the equation.

There are other colour systems like Natural Colour System ${ }^{\circledast}$ (NCS). NCS is based on how we perceive colour visually, so the system allows us to describe colour on all kinds of surfaces. According with the company, all surface colours can be described with a NCS Notation (NCS, 2019).

The NCS is based on the six elementary colours which are perceived by human beings and is illustrated in a threedimensional colour space. According with NCS website if we have, for example, the colour NCS S 1050-R90B we have $10 \%$ in blackness and $50 \%$ in chromaticness. The whiteness is then: $100 \%-10 \%-50 \%=40 \%$. About the Hue, we have $90 \%$ of red and $10 \%$ of blue.

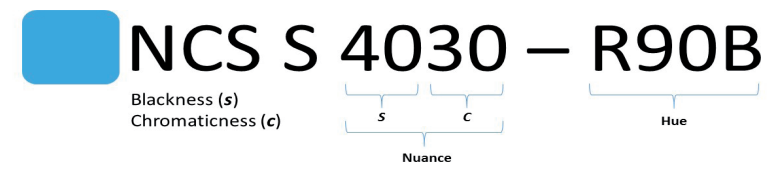

This system could be adapted and applied in the retouching process. Although is not possible to write the artist colours in this way because the number of colours and mixing are more diverse.

\section{Starting point: reading the label}

Knowing to read a label is crucial to specify the colour mixing. In Figure 1 it is possible to identify the different segments of the watercolours label from Winsor \& Newton. Two of the most important things is the Colour 
name and the Pigments number. The first one is the name of the colour. These are not necessarily unique to a range or medium, e.g. Cerulean Blue exists in Watercolour and Oil Colour. The Pigments Number represents the Colour Index Generic Name, because each pigment can be identified by a name. For example, Cobalt Blue is Pigment Blue 28, so the pigment is abbreviated to PB 28. More than one pigment abbreviation indicates multiple pigments in the tube or pan.

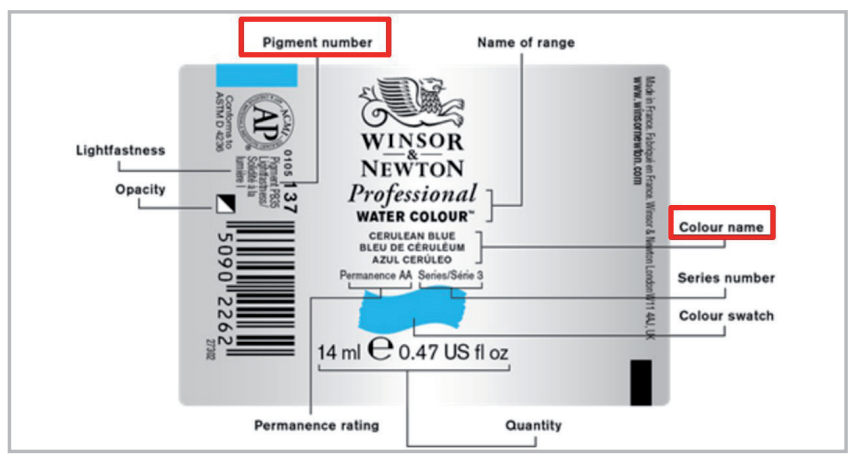

Figure 1.- Label of the Watercolour. Professional, Winsor \& Newton. Available on Winsor\&Newton website

\section{Creating Equations}

In order to further explain this proposal, three Professional Watercolour of Winsor and Newton [Figure 2] will be used: the lemon yellow (PY175), the winsor red (PR254) and the cobalt turquoise blue, made by the mixing of two blues (PB28, PB36).
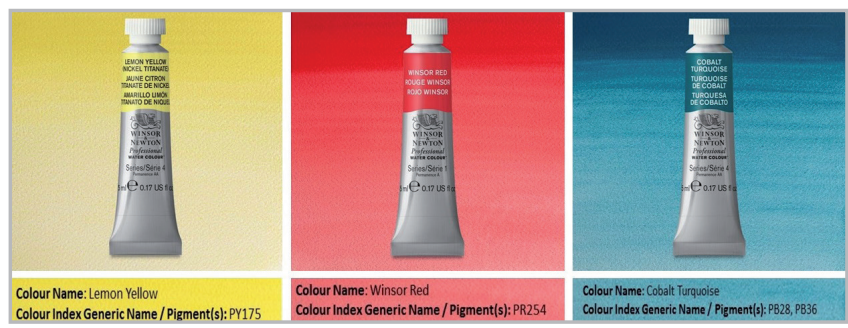

Figure 2.- Professional Watercolour, Winsor \& Newton

\section{Guidelines}

After identification of the pigments inside the tubes the next step would be to specify the mixings made outside the tube. Thus, it would be necessary to define the basic guidelines, such as:

1. The colour portions are represented with curved parenthesis ( )

2. The colour of the tube/pan is represented with straight parenthesis [ ]

3. To write the colour the Colour Index Generic Name or pigment abbreviation is used

4. The mathematical symbol is always Plus because the colours are added to get the mix.

5. The Comma is used to represent mixings inside of a tube/pan

6. The abbreviation for mixing is the letter " $m$ " in italic.
For example, to write that we use a portion of lemon yellow with 2 parts of winsor red we can state as follows:

$$
\text { [PY 175] (1) + [PR 254] (2) }
$$

When we are adding mixtures the best way is to simplify the equation. For example, using 1 portion of lemon yellow with 2 parts of a mixture made with 1 part of winsor red and 2 of cobalt turquoise, it can be stated as follows:

$1^{\circ}$ First the mixing of 1 part of winsor red with/plus 2 parts of cobalt turquoise is recorded:

$$
[P R 254](1)+[\text { PB28, PB 36] }(2)=m
$$

$2^{\circ}$ Then the equation is concluded:

$$
[P Y 175](1)+[m](2)
$$

But, if we have two mixtures, "a" and " $b$ " are needed after the " $m$ ". So, for a first colour mixing we can have " $m$ " and if we had a second mixing we have " $m a$ ", " $m b$ " and so on.

\section{Creating Colorized Equations}

Equations can also be colorized to help the reader to understand the diagram. In this way our eyes could read the equation like a map and not a string of symbols. The technical description of the retouching process recorded in this manner seems much clearer to comprehend. Furthermore, each of the symbols can have its own distinct colour:
1. Curved parenthesis ( ) in blue.
2. Straight parenthesis [ ] in green
3. Colour Index Generic Name or pigment abbreviated in black

\section{Sign plus in black}
5. Comma in red
6. Letters " $m$ ", " $a$ ", " $b$ " in black and italic.

Using the same equations as above the coloured symbols can be implemented as follows:

$$
\begin{gathered}
\text { [PY 175] (1) + [PR 254] (2) } \\
{[\text { PR 254] (1) }+[\text { PB28, PB 36] }(2)=m} \\
{[\text { PY 175] (1) }+[m](2)}
\end{gathered}
$$

\section{Conclusions remarks}

In this article, the main idea was to propose a fast colorized equation to help describing the retouching pigments/ paints used for the restoration treatment. This is an ongoing project. A number of directions can be pursued, and improvements can be made. Creating colorized equations is not new, but adapted them to the retouching painting is a challenge, especially to help in the daily work of learning 
students and conservators-restorers. The development of a precise system to record the used pigments, their quantities and the way their mixtures are made is essential for a transparent treatment and future interventions. The conservator-restorer could use the spectrophotometer to compare the final and original hues, but to explain how the colour was obtained it is necessary to use all relevant information about the ingredients of the paint.

\section{Notes}

[1] This information was taken from the blog "The watercolour Log" of Peter Ward that contact Winsor\&Newton. «l have received the following reply to my queries from Debbie at Winsor \& Newton:'Since we have developed Cadmium Free colours we cannot give the pigments away for other companies to use. We have spent years perfecting these colours to mimic as close as possible the original Cads and we are protecting our own interests.» Available at: https://watercolourfanatic.blogspot. com/2019/03/winsor-newton-cadmium-free-watercolours.html [accessed 10/01/2020].

\section{References}

BAILÃO, A. (2013). "O sistema das nove cores na reintegração cromática de bens culturais". Ge-conservación, n.5, 110-134. https://www.ge-iic.com/ojs/index.php/revista/article/view/171. [accessed 12/01/2020]

BERRIE, B.H., LOMAX, S. Q. (1997). "Azo pigments: Their History, Synthesis, Properties, and Use in Artist's Materials". Conservation Research 1996/1997. 09- 33. https://www.nga.gov/content/ dam/ngaweb/research/publications/pdfs/conservationresearch-1996-1997.pdf [accessed 20/12/2019].

BYRNE, A., HILBERT, D.H., (2003). "Color realism and color science". Behavioral and brain sciences, 26, 3 -64. http://web.mit.edu/abyrne/ www/colorrealismandcolorscience.pdf [accessed 28/02/2020].

EASTAUGH, N.; WALSH, V.; CHAPLIN, T.; SIDDALL, R. (2008). Pigment Compendium. A Dictionary and Optical Microscopy of Historical Pigments. Amsterdão, Boston, Londres: Butterworth-Heinemann.

JOHNSTON-FELLER, R. (2001). Color Science in the Examination of Museum Objects. Nondestructive Procedures. Tools for Conservation. Los Angeles: Getty Conservation Institute, 296-297.

KSIAZKIEWICZ, A. (2013). "The surface of things: the problem of describing colour". Viewpoint, 102, 16- 17. https://www.academia. edu/7019363/The surface of things the problem of describing colour [accessed 18/12/2019].

MARTEL, C. (1855). Principles of colouring in Painting. Londres: Winsor and Newton.

NCS (2019). "NCS- Natural Colours System". https://ncscolour. com/ncs/ [accessed 22/11/2019].
NEMCSICSA A., CAIVANO, J.L. (2015). "Color Order Systems". Encyclopedia of Color Science and Technology, 1-16, https://doi. org/10.1007/978-3-642-27851-8 232-7 [accessed 19/12/2019].

PYLE, D.; PEARCE, E. (2009). The Oil Colour Book. A comprehensive resource for painters. Harrow, Inglaterra: ColArt Fine Art \& Graphics Ltd, p. 17. http://www.winsornewton.com. [Consulta: 19. 05. 2013].

SOCIETY OF DYERS AND COLOURISTS (2019). Colour Index ${ }^{\mathrm{TM}}$ Generic Name (CIGN). https://colour-index.com/colour-index-genericname [accessed 20/11/2019]

URLAND A. (1999). “Conservation of Architectural Heritage Historic Structures and materials. Colour Specification and Measurement" ICCROM UNESCO WHC, ISBN 92-9077-157-7, https://www.iccrom. org/sites/default/files/ICCROM 14 ARCLabHandbook03 en.pdf [accessed 20/12/2020], 2-3.

URLAND, A. (1999). Colour Specification and measurement. Conservation of Architectural Heritage, Historic Structures and Materials. ARC Laboratory Handbook. Rome: ICCROM UNESCO WHC, Vol.5.

X-RITE (2015). A Guide to Understanding color, 23-29 https://www. xrite.com/-/media/xrite/files/whitepaper pdfs/l10-001 a guide to understanding color communication//10-001 understand color en.pdf. [accessed 24/01/2020]

\section{Author/es}

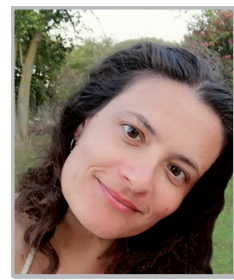

\section{Ana Bailão}

ana.bailao@gmail.com

Faculdade de Belas-Artes (CIEBA); Centro de Investigação em Ciência e Tecnologia das Artes (CITAR), Universidade Católica Portuguesa

Diploma in Conservation and Restoration by the Polytechnic Institute of Tomar (2005) and a master's degree in Painting Conservation by the Portuguese Catholic University (2010). The master research was about methodologies and techniques of retouching. $\mathrm{PhD}$ in Conservation of Paintings at the same university, in collaboration with the Centro de Investigação em Ciência e Tecnologia das Artes (CITAR) and the Instituto del Patrimonio Cultural de España (IPCE), Madrid. The doctoral research was about the criteria and methodologies which might help to enhance the quality of painting retouching. The projects are presented through publications, lectures, exhibitions and presentations. Teaching about conservation and restoration, especially chromatic retouching, since 2008. Since 2004 carrying out conservation and restoration works. 